\title{
Digital Financial Inclusion, Spatial Spillover, and Household Consumption: Evidence from China
}

\author{
Yao Li $(\mathbb{D}$, Haiming Long $\mathbb{D}$, and Jiajun Ouyang $(\mathbb{D}$ \\ College of Finance and Statistics, Hunan University, Yuelu District, Changsha, Hunan, 410006, China \\ Correspondence should be addressed to Jiajun Ouyang; tahoyou@hnu.edu.cn
}

Received 18 June 2021; Revised 15 November 2021; Accepted 7 January 2022; Published 25 February 2022

Academic Editor: Haitao Ma

Copyright $\odot 2022$ Yao Li et al. This is an open access article distributed under the Creative Commons Attribution License, which permits unrestricted use, distribution, and reproduction in any medium, provided the original work is properly cited.

\begin{abstract}
Financial development is often considered one of the main drivers promoting household consumption. As a form of financial development, whether digital financial inclusion can promote household consumption has been a concern for researchers and policymakers. Considering geographical connectivity characteristics, we examine the effects of digital financial inclusion on household consumption by applying spatial econometric models and using data from 31 provinces in China from 2013 to 2018. The impact of digital financial inclusion is further disaggregated into direct, indirect, and total impacts. The results show that if digital financial inclusion is improved by $1 \%$, household consumption will correspondingly increase by $0.2207 \%$. The spatial spillover effect on neighboring areas is negative: a $1 \%$ increase in the level of digital financial inclusion of nearby provinces leads to a $0.1289 \%$ decrease in household consumption in the local province. For policymakers, it is necessary to balance the development of digital financial inclusion and view different areas as a whole when making policies to promote consumption. Further analysis based on subsamples finds that the effect of digital financial inclusion on household consumption is more considerable for rural households than for urban households.
\end{abstract}

\section{Introduction}

Consumption, investment, and export have been described as the "three drivers" of economic growth in China for a long time. However, under the circumstances of slow global economic growth and complex international relationships due to the prevalence of COVID-19, China's net exports show signs of decline. China's net export was RMB 15057.1 billion in 2010 and RMB 11397.9 billion in 2019, a decrease of $24.30 \%$. During the same period, investment, which has long been the largest engine of economic growth in China, also shows a slowing growth rate, with its contribution to GDP growth falling from $47 \%$ in 2010 to $43.1 \%$ in 2019 . As investment and export hit bottlenecks in China, consumption is playing an increasingly fundamental role in economic growth. Its contribution to economic growth rose from $49.3 \%$ in 2010 to $55.8 \%$ in 2019 . This indicates that China's economy has transformed from investment-driven growth and export-driven growth into consumption-driven growth, and consumption has become the most considerable driving force. The Fifth Plenary Session of the 19th Central Committee proposed emphasizing the "domestic cycle", which means stimulating domestic demand and making consumption the main engine of economic development. Therefore, under the new normal of China's economy, expanding domestic demand and promoting consumption are of great significance to China's sustainable development.

Thanks to the development of innovative technologies, such as big data, the Internet, and cloud computing, digital financial inclusion has experienced exponential growth since the late 2000s and early 2010s. According to the digital financial inclusion index, the index increases from 40 in 2011 to 300 in 2018. Digital financial inclusion provides various services to residents, including mobile payments, online loans, online insurance, and Internet finance. By the end of 2020, mobile payment had 854 million users, accounting for $86.4 \%$ of the total number of netizens in China, and its transaction value had reached RMB 200 trillion. "Huabei" and "Jiebei", online consumer loan services launched by AliFinance, had offered loans up to USD 95 billion by the 
first quarter of 2018, nearly 3.7 times the amount of loans launched by the China Construction Bank [1]. In recent years, 12.29 billion new Internet insurance policies have been issued, accounting for $71 \%$ of the number of new insurance policies. Yu'E Bao, the country's largest online money market fund, was launched in June 2013 by Alipay. By the first quarter of 2014, it had more than 15 million users and assets reaching RMB 250 billion.

Financial development plays a pivotal role in boosting household consumption. It can promote efficient resource allocation and smooth intertemporal consumption, thus relieving residents from liquidity constraints and increasing consumption demand [2]. As a form of financial development, digital financial inclusion influences household consumption in an irreplaceable way. Some studies have studied the relationship between digital financial inclusion and household consumption, but few take spatial links into account. However, according to the first law of geography, everything is alike and correlated to each other [3]. First, because of the large territory and great economic and geographic heterogeneity, there are tremendous differences between provinces. As a result, geographical disparities in household consumption and digital financial inclusion are apparent. However, with the improvement in infrastructure, the popularization of Internet technology, and the issuance of interprovincial cooperation policies, communication across regions is becoming closer. Factors of production, such as talent and technology, thus flow more frequently. Consequently, household consumption and the development of digital financial inclusion show spatial correlation characteristics. Additionally, as provinces become more closely linked, the socioeconomic situation of one province might exhibit a remarkable demonstration effect [4] or crowding-out effect [5] on neighboring provinces immediately or within a short period [6]. Therefore, identifying the spatial distribution and taking spatial correlation into account are meaningful when exploring the relationship between household consumption and digital financial inclusion.

This paper contributes to the relevant research in three dimensions. First, the attributes of entities that are adjacent to each other are prone to be similar. Spatial econometrics takes spatial agglomeration and the evolution of spatialtemporal patterns into account. This approach is chiefly used to investigate environmental economics and is hardly applied to studies on digital financial inclusion and household consumption. In this paper, we use the global Moran's I index and local Moran's I index to describe their spatial autocorrelation characteristics in China. Second, the existing research considering the relationship between digital financial inclusion and household consumption assumes that spatial objects with adjacent geographical locations are not related. Based on SDM, we analyze the spatial spillover effects in China, taking the effect of neighboring provinces into account. This method is particularly useful for providing suggestions to policymakers about how to optimize household consumption among different areas to create win-win situations. Third, recent studies tend to regard the effect as a whole and seldom consider the difference between disadvantaged people in rural districts and the main groups in urban districts. However, by comparing the empirical results of these two groups, we find that digital financial inclusion has significantly distinct impacts on household consumption in China.

The rest of this paper is organized as follows: Section 2 presents an overview of the related literature and proposes research hypotheses. Section 3 introduces the adopted data, variables, and empirical model. Section 4 exhibits the empirical results, associated interpretations, endogeneity tests, and robustness tests. Section 5 concludes.

\section{Literature Review and Research Hypotheses}

Financial inclusion can ease the exclusiveness of traditional finance. The development of digital financial inclusion can improve financial services' accessibility, coverage, and efficiency [7]. Especially for unbanked residents, digital financial inclusion expands the channels by which they can obtain access to and actively use affordable financial services that can meet their various financial needs [8]. Zhong and Jiang (2020) empirically demonstrated this viewpoint by using daily peer-to-peer (P2P) lending data from multiple platforms in China. They found that digital financial inclusion can reduce the asymmetry in traditional financial markets and thus weaken the exclusiveness of traditional finance [9]. As long as consumers have digital devices that can access the Internet, they can experience services offered by digital financial inclusion [10].

Digital financial inclusion has a significantly positive impact on household consumption [11, 12]. More precisely, digital financial inclusion is expected to influence household consumption in several aspects by providing different kinds of services. First, mobile payments make it easier for consumers to make purchases. It can avoid the situation in which residents do not have enough cash, thus accelerating the process of consumption decisions and increasing the likelihood of consumption [12]. In addition, mobile payments can significantly stimulate household consumption through a "mental account". The theory argues that the psychological loss caused by digital transactions is lower than that caused by cash transactions [13]. Moreover, by lowering the threshold of entry and reducing the impacts of distance on trade, mobile payments promote the emergence of e-commerce. E-commerce can not only enrich the diversity of commodities but also reach disadvantaged consumers who were previously not served [14]. Second, the life and transaction data of residents can be accumulated through big data, thus improving information asymmetry and helping individuals obtain credit easily and quickly. As a result, their liquidity constraints can be relieved [15-17]. Third, on the one hand, the development of online insurance can intensify competition among insurance companies and facilitate the upgrading of the traditional insurance industry. On the other hand, it can also enrich the types of products and improve insurance accessibility, which encourages consumers to buy insurance, reduces their uncertainty losses, and improves their sense of security [18]. Fourth, the emergence of Internet finance lowers the threshold of investment services, improves investment convenience, and provides subsidy channels [19]. For example, by expanding the approaches to investments with a small amount of money, Yu'E Bao increases investment returns and household wealth. 
Based on the analysis, this paper proposes the following hypothesis:

Hypothesis 1. (H1). The development of digital financial inclusion can promote household consumption.

In theory, digital finance does not need to rely on physical outlets. As a result, it has greater geographical penetration and can save costs. However, as a new form of finance, digital finance still needs to follow the basic rules of financial development. On the one hand, its development still depends on the real economy and traditional finance. Digital finance evolves as the innovative superposition of traditional finance, and the two are mutually integrated and complementary [20]. On the other hand, the factors that influence the development of digital finance may have much in common with those that affect the real economy and traditional finance. These factors are usually spatially related, such as GDP, the Internet, industrial structure, population density, and openness [21]. Moreover, the promotion and diffusion of digital finance depend on geography. For example, Ant Financial is headquartered in Hangzhou. If the company wants to promote business in other places, the level of difficulty is positively related to the distance from Hangzhou. This rule has been repeatedly emphasized in traditional economic geography, and digital finance can hardly escape it. In addition, digital finance originated from online shopping and online payment. Due to express delivery and other factors, online shopping is highly geographically dependent, as shown taking "free delivery" in Jiangsu, Zhejiang, and Shanghai as an example [22].

Second, with the improvement in the transportation system and the decrease in communication costs, communication between different provinces is becoming closer in China, and production factors can easily flow from one region to another $[14,23]$. This situation is beneficial to the exchange of resources and the sharing of information between adjacent provinces regarding the development of digital financial inclusion [21].

Third, the mode of governmental guidance "from points to areas; parts pushing the whole" makes spatial agglomeration the characteristic of the level of digital financial inclusion [24]. In addition, governments tend to learn from and imitate each other when making policies, thus forming province clusters and further promoting the spatial agglomeration of the level of digital financial inclusion.

Therefore, although digital financial inclusion can have some hypergeographic characteristics, in theory, it cannot eliminate geographical restrictions in reality and shows strong spatial agglomeration [25-28].

Regarding the spatial effect of digital financial inclusion on household consumption, on the one hand, the development of digital financial inclusion can increase household consumption, and it presents spatial correlation. The development of digital financial inclusion in nearby places can affect the development of digital financial inclusion in a province, thus indirectly increasing household consumption in the area [29]. Therefore, the development of digital financial inclusion in nearby places might contribute to the growth of household consumption in a particular place. On the other hand, unbalanced digital financial inclusion development may intensify interprovincial competition in resource distribution. As a result, the economy of provinces with a higher level of digital financial inclusion prospers, siphoning increasingly more resources from less-developed provinces and impeding their development, thus negatively affecting household consumption [24]. Therefore, the development of digital financial inclusion in nearby places might bring about a crowding-out effect and decrease household consumption in a particular district [5].

Based on the analysis, this paper proposes the following hypothesis:

Hypothesis 2. (H2). The development of digital financial inclusion has a spatial effect on household consumption.

\section{Methodology}

3.1. Data. The household data and control variables are from the China Statistical Yearbook released by the National Bureau of Statistics. The calculated calibers of household consumption before 2013 and after 2013 are different. After considering the comparability of the data, we decide to use the data after 2013.

The digital financial inclusion index was compiled by Alipay and the Internet Finance Institute of Peking University from 2011 to 2018 to reflect the level of digital financial inclusion in China. Table 1 shows the components of the comprehensive index. The index consists of three dimensions: coverage, depth, and digital support services. There are three levels of indexes available: provincial, $\mathrm{mu}-$ nicipal, and county.

Based on the principles of availability and consistency, we use data from 31 provinces in China from 2013 to 2018.

3.2. Spatial Econometric Model. The existing literature illustrates various factors that impact household consumption [30-32]. Based on these, we choose the following control variables: household income, human capital, transport infrastructure, fiscal expenditure, industrial structure, openness, and population density. Table 2 shows how those variables are defined.

To empirically investigate how digital financial inclusion affects household consumption, we exhibit a baseline regression model as follows:

$$
\begin{aligned}
\ln \mathrm{Con}_{i t}= & \beta_{0}+\beta_{1} \ln \mathrm{DFI}_{i t}+\beta_{2} \ln _{\mathrm{Incom}_{i t}}+\beta_{3} \ln \mathrm{Hum}_{i t}+\beta_{4} \text { Trans }_{i t} \\
& +\beta_{5} \text { Fisc }_{i t}+\beta_{6} \text { Indsu }_{i t}+\beta_{7} \text { open }_{i t}+\beta_{8} \text { Pop }_{i t}+u_{i}+\varepsilon_{i t},
\end{aligned}
$$


TABLe 1: Components of the digital financial inclusion index.

\begin{tabular}{lcc}
\hline & Level 2 indexes & Level 3 indexes \\
\hline & Coverage & Coverage of account \\
Coverage depth & Coverage of account payment & Payment insurance \\
Inital financial inclusion index & & Insurance investment \\
& & Investment monetary fund \\
& Mepthetary fund credit & Credit loan \\
& & Loan convenience \\
& Digital support services & Convenience cost \\
\hline
\end{tabular}

TABLE 2: Variable definition.

\begin{tabular}{|c|c|c|}
\hline Variables & Symbol & Definition \\
\hline Household consumption & Con & The aggregate household expenditure \\
\hline Digital financial inclusion & DFI & $\begin{array}{c}\text { Digital financial inclusion index compiled by Alipay and Internet finance } \\
\text { institute of Peking university }\end{array}$ \\
\hline Household income & Incom & The aggregate household income \\
\hline Human capital & Hum & The number of students enrolled in colleges and universities \\
\hline Transport infrastructure & Trans & The sum of paved roads and railways/total area of province \\
\hline Fiscal expenditure & Fisc & The aggregate of government expenditure/GDP \\
\hline Industrial structure & Indus & The added value of the tertiary industry/GDP \\
\hline Openness & Open & The total value of imports and exports/GDP \\
\hline Population density & Pop & The total population/total area of province \\
\hline
\end{tabular}

where $\beta_{k}$ is the kth parameter to be estimated; $i$ represents the province, and $t$ represents the period; $u_{t}$ represents the time fixed effect; and $\varepsilon_{i t}$ is the residual error.

Table 3 presents the descriptive statistics of the independent variable, dependent variables, and control variables. As Table 3 shows, the average household consumption is RMB 16,443.12, and the average digital financial inclusion index is 226.2849. The maximum value of household consumption is RMB 43351.3, which is more than six times the minimum value (RMB 6306.79). This implies that there is a significant disparity in consumption between different provinces. The maximum value of digital financial inclusion is 377.7337 , while the minimum value is 115.1 , indicating substantial inequality in the development of digital financial inclusion in China.

Equation (1) does not consider the spatial dependence between entities. However, the household consumption of adjacent provinces may affect the household consumption of a province, as may the development of neighboring areas. This is an inherent shortcoming of traditional econometric models, which consider cross-sectional units to be unrelated. Spatial econometrics is an effective method to evaluate geographical dependency. Next, we introduce spatial econometric models to take geographical dependency into consideration. The spatial Durbin model below is specified for this purpose:

$$
\begin{aligned}
& \ln \operatorname{Con}_{i t}=\beta_{0}+\rho \sum_{j=1}^{N} w_{i j} \ln \operatorname{Con}_{j t}+\beta_{1} \mathrm{DFI}_{i t}+\beta_{2} \ln \operatorname{Incom}_{i t}+\beta_{3} \ln \operatorname{Hum}_{i t}+\beta_{4} \text { Trans }_{i t} \\
& +\beta_{5} \text { Fisc }_{i t}+\beta_{6} \text { Indsu }_{i t}+\beta_{7} \text { open }_{i t}+\beta_{8} \text { Pop }_{i t} \\
& +\theta_{2} \sum_{j=1}^{N} w_{i j} \ln \mathrm{DFI}_{j t}+\theta_{2} \sum_{j=1}^{N} w_{i j} \ln _{\operatorname{Incom}_{j t}}+\theta_{3} \sum_{j=1}^{N} w_{i j} \ln \operatorname{Hum}_{j t} \\
& +\theta_{4} \sum_{j=1}^{N} w_{i j} \operatorname{Trans}_{j t}+\theta_{5} \sum_{j=1}^{N} w_{i j} \text { Fisc }_{j t}+\theta_{6} \sum_{j=1}^{N} w_{i j} \sum_{j=1}^{N} w_{i j} \text { Indus }_{j t} \\
& +\theta_{7} \sum_{j=1}^{N} w_{i j} \text { Open }_{j t}+\theta_{8} \sum_{j=1}^{N} w_{i j} \operatorname{Pop}_{j t}+\varepsilon_{i t} \\
& \varepsilon_{i t}=\lambda w \varepsilon_{i t}+\mu_{i t},
\end{aligned}
$$


Table 3: Descriptive statistics.

\begin{tabular}{lccccc}
\hline Variables & Mean & Std. Dev. & Min & Max & Obs \\
\hline Con & 16443.12 & 6715.299 & 6306.79 & 43351.3 & 186 \\
DFI & 226.2849 & 55.47315 & 115.1 & 377.7337 & 186 \\
Incom & 22914.17 & 10036.82 & 9740.43 & 64182.65 & 186 \\
Hum & 855996.5 & 526122.5 & 33474 & 2140780 & 186 \\
Trans & 9.426809 & 5.299249 & 0.5916085 & 21.74448 & 186 \\
Fisc & 0.2860584 & 0.2115872 & 0.1207761 & 1.379157 & 186 \\
Indus & 0.0735436 & 0.0131422 & 0.0560575 & 0.1273875 & 186 \\
Open & 0.0735436 & 0.0131422 & 0.0560575 & 0.1273875 & 186 \\
Pop & 0.0452295 & 0.0692612 & 0.0002595 & 0.3826197 & 186 \\
\hline
\end{tabular}

where $w_{i j}$ is the spatial weight matrix; $\rho$ is the spatial autoregression coefficient, which reflects the spatial spillover effect of the dependent variable; $\theta$ is the spatial lag coefficient, which reflects the spatial spillover effect of the independent variables; $\varepsilon_{i t}$ is the residual error; $\lambda$ is the spatial autoregression coefficient of the residual error; and $u_{i t}$ is the specific effect.

Equation (2) is the spatial Durbin model (SDM) and can be simplified into the spatial autoregression model (SAR) and spatial error model (SEM). If $\theta=0$, the SDM can be transformed into an SAR. If $\theta+\rho \beta=0$, the SDM can be transformed into an SEM. The Wald test and likelihood ratio (LR) test examine whether $\theta=0$ and $\theta+\rho \beta=0$, respectively. These tests are performed below.

3.3. Spatial Weight Matrix. The selection of the spatial weight matrix is pivotal when constructing spatial models because a matched matrix can support the validity of the judgment and estimation. The most commonly used matrices are the adjacent spatial weight matrix, geographical distance spatial weight matrix, economic distance weight matrix, and relative threshold weight matrix [33]. Because of the unique structure of different provinces in China, applying the geographical distance spatial weight matrix, economic distance weight matrix, or relative threshold weight matrix is unreasonable [34]. Accordingly, the adjacent spatial weight matrix remains the only choice.

An adjacent spatial weight matrix is set based on the criteria of contiguity. $w_{i j}=1$ means $i$ and $j$ share a boundary; otherwise, $w_{i j}=0$ :

$$
w_{i j}= \begin{cases}1, & i \text { is adjacent to } j, \\ 0, & i \text { is not adjcent to } j\end{cases}
$$

\section{Empirical Analysis}

4.1. Spatial Distribution Analysis. To better understand the spatial distribution characteristics of household consumption and the level of digital financial inclusion in China, we draw spatial distribution maps of 31 provinces in mainland China in 2013 and 2018 (Figures 1 and 2).

Household consumption is shown in Figure 1. In 2013, the five provinces with the most household consumption were Shanghai, Beijing, Zhejiang, Tianjin, and Jiangsu, which are all located in the eastern areas, while the five provinces with the least household consumption were Tibet, Guizhou, Yunnan, Gansu, and Guangxi, which are all in the west. The household consumption of Jilin and Tibet is the highest among provinces in the central and western districts, respectively, but the average household consumption of eastern districts (RMB 18276.33091) is almost twice as high as that of Jilin (RMB 12054.34) and nearly three times that of Tibet (RMB 6306.79).

In 2018, household consumption increased from RMB 13307.11226 to RMB 19787.75613. The top five provinces and the last five provinces in terms of household consumption are the same as those in 2013. Households living in Hubei consume the most (RMB 19537.79) among central provinces, but the number is still slightly smaller than the average number of households in the whole country. Inner Mongolia has the highest household consumption (RMB 19665.22) among provinces in the west, but it is still less than the national average.

On the whole, household consumption in China is undoubtedly unbalanced. There is a gradient transfer characteristic from east to west, indicating that household consumption is high in the east but low in the west. Although the sum of household consumption of each province increases during the corresponding sample period, the pattern of distribution is relatively stable. This phenomenon is partly because of the geographical location and economic development plan of China. Due to its vast territory, China is usually separated into three parts: the western region, the central region, and the eastern region ${ }^{1}$. The eastern areas have long coastlines, which is the most prominent difference from provinces in the western region, while the provinces in the west are all inland and far from the coast [35]. Because of their geographical advantage, eastern provinces opened up earlier and thus attracted more foreign investment than other provinces. The government's preference for supporting eastern provinces further intensifies the imbalance of economic development among different areas. In the later period of China's reform and opening up, China gradually opened up to foreign investors and international markets, from the coastal to the middle and inland areas. Geographical features and governmental policies contribute to disproportionate financial development, with the eastern provinces developing much faster than the central and western provinces. Accordingly, families living in the east are wealthier than those in the west, thus consuming more.

The development of digital financial inclusion is shown in Figure 2. In 2013, the five provinces with the highest level of digital financial inclusion were Shanghai, Beijing, Zhejiang, Fujian, and Guangdong, which are all located around Hangzhou (where the headquarters of Ant Financial are located). The five provinces with the lowest levels were Sichuan, Tibet, Gansu, Qinghai, and Ningxia, which are far from the coast. In 2018, the level of digital financial inclusion increased from 155.75 to 300.21 . The top five provinces in terms of the level of digital financial inclusion were Shanghai, Beijing, Zhejiang, Fujian, and Jiangsu, while the last five were Inner Mongolia, Gansu, Qinghai, Ningxia, and Xinjiang.

On the whole, the development of digital financial inclusion presents a characteristic of spatial heterogeneity. The eastern coastland, where Hangzhou is located, gathers 


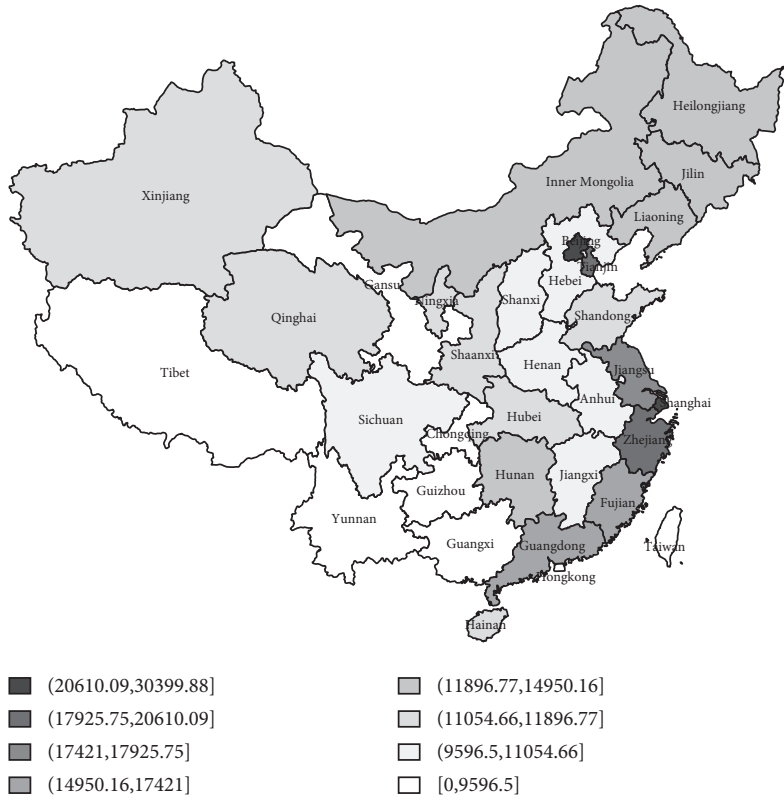

(a)

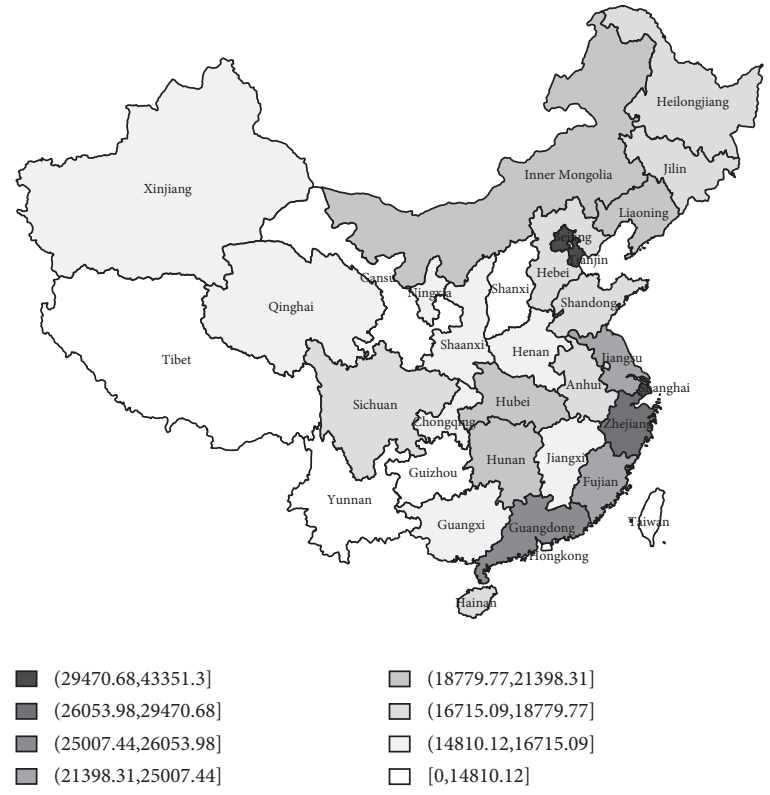

(b)

FIGURE 1: Spatial distribution of household consumption in 2013 (a) and 2018 (b).

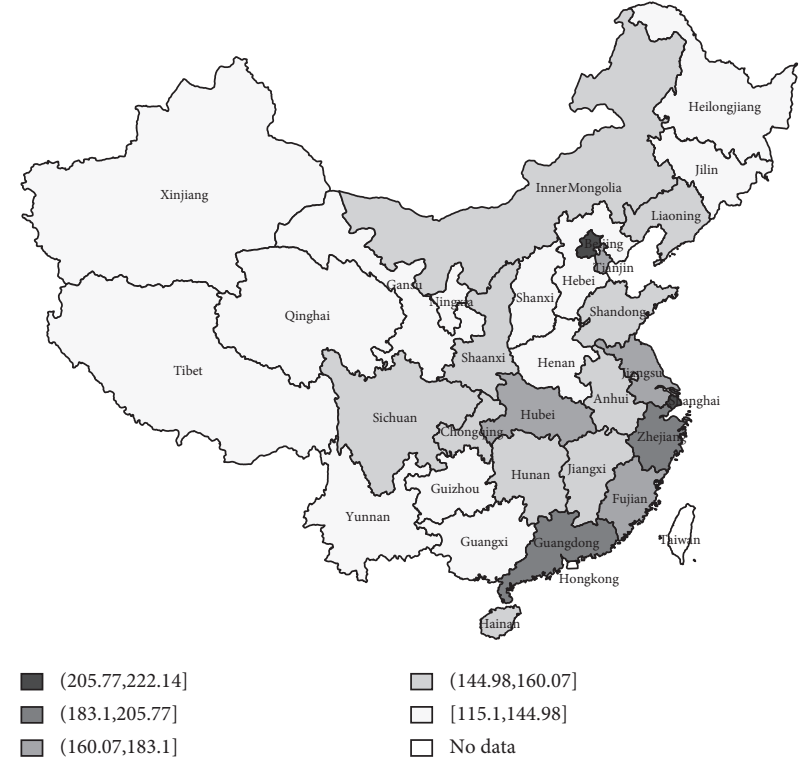

(a)

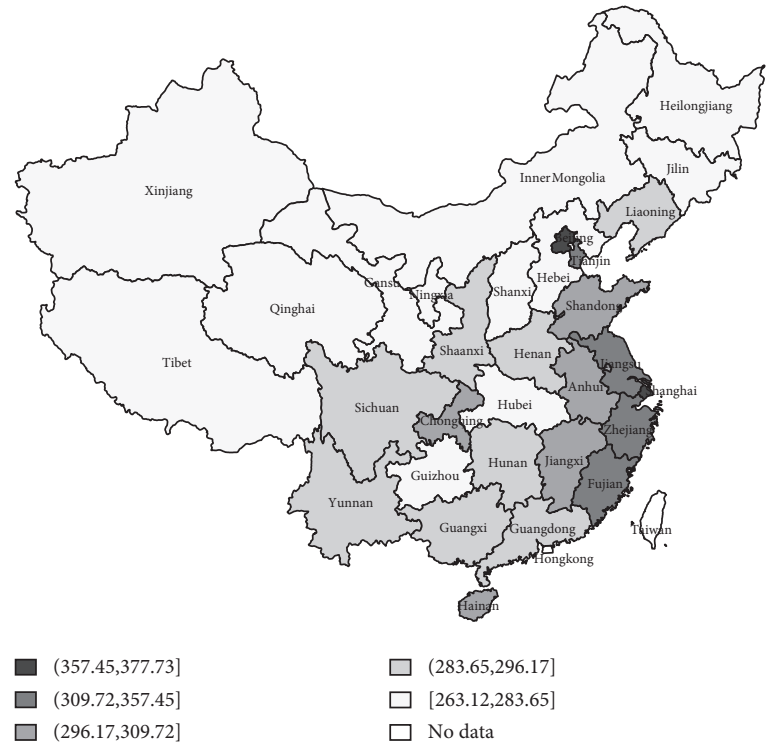

(b)

FIGURE 2: Spatial distribution of the development of digital financial inclusion in 2013 (a) and 2018 (b).

provinces with advanced digital financial inclusion, while high-level provinces are relatively scarce in the central and western regions. This phenomenon implies that the development of digital financial inclusion still depends on geography. That is, the closer a province is to Hangzhou, the higher its development of digital financial inclusion. This is partly because the promotion and diffusion of digital finance depend on geography.

Based on the analyses above, we conclude that the spatial distribution of China's household consumption presents a ladder distribution from coastal to inland areas and has a steady- state characteristic. The levels of digital financial inclusion in China basically decline from Hangzhou to its neighbors.

4.2. Spatial Autocorrelation Analysis. Spatial autocorrelation measures aim to investigate the spatial relationship between entities with adjacent geographical locations [36]. The Moran's I index, Geary coefficient, and Getis index can be used to examine spatial autocorrelation and spatial agglomeration. Among them, the Moran's I index is the most frequently used. If an entity is affected by others around, 
spatial correlation exists. This is not in accordance with the basic premise of traditional statistics and makes most statistical tests invalid, so the tests are essential. The Moran's I index consists of the global Moran's I index and local Moran's I index.

The global Moran's I test measures how similar an entity is to others that are geographically nearby $[37,38]$. Similar to the correlation coefficient, the global Moran's I index is distributed in $[-1,1]$. The coefficient is high when the absolute value of the autocorrelation coefficient is high. When the global Moran's I index varies between $[0,1]$, it indicates that the entity is positively correlated with others. When the index varies between $[-1,0]$, it means that the correlation is negative. A value of 0 implies no correlation.

Based on the adjacent spatial weight matrix, we use the global Moran's I to test the spatial autocorrelation of household consumption and the level of digital financial inclusion of 31 provinces in China from 2013-2018. Table 4 displays the results. As shown in Table 4, the global Moran's I indexes are between $[0,1]$, and all are significant at the $1 \%$ level, implying that household consumption and the level of digital financial inclusion in China are positively autocorrelated in space. In addition, the global Moran's I index basically increases over time, especially after 2015, which implies that the spatial autocorrelation strengthens with continuous socioeconomic development [39].

The results above imply that provinces with similar levels of household consumption and digital financial inclusion are prone to concentrate geographically. To further explore the spatial effects at the provincial level, scatter plots of the local Moran's I index are drawn (Figures 3 and 4). Local Moran's I scatter plots can divide household consumption into four quadrants that denote four kinds of agglomerations. Quadrant I indicates high-high (HH) agglomeration, which means that provinces with high household consumption are near to each other. Quadrant III reflects low-low (LL) agglomeration; that is, if a province with low household consumption falls into quadrant III, the provinces nearby also have lower consumption. Quadrants II and IV represent low-high (LH) agglomeration and high-low (HL) agglomeration, respectively, which means that a province with low household consumption is surrounded by provinces with high household consumption, and vice versa.

For the results of household consumption shown in Figure 3, most of the provinces are located in quadrant I and quadrant III, which means that most provinces have similar characteristics to their neighbors, in line with the spatial cluster characteristic detected by the global Moran's I index. In 2013, 6 provinces fall into quadrant I and 16 provinces into quadrant III, occupying $70.97 \%$ of the total number of samples. The number of provinces located in quadrant I and quadrant III is the same in 2014 and 2013. In 2015, 6 provinces are in quadrant $\mathrm{I}$, and 17 provinces are in quadrant III, with a proportion of $74.19 \%$. The situation in 2015 persists into 2016 and 2017. In 2018, 6 provinces are located in quadrant I, and 19 provinces are in quadrant III, accounting for $80.65 \%$.

For the level of digital financial inclusion, the same characteristics of positive spatial agglomeration can be
TABLE 4: Global Moran's I indexes (2013-2018).

\begin{tabular}{lcc}
\hline \multirow{2}{*}{ Year } & \multicolumn{2}{c}{ Global Moran's I index } \\
& Household consumption & Digital financial inclusion \\
\hline 2013 & $0.371^{* * *}$ & $0.456^{* * *}$ \\
2014 & $0.373^{* * *}$ & $0.453^{* * *}$ \\
2015 & $0.372^{* * *}$ & $0.416^{* * *}$ \\
2016 & $0.362^{* * *}$ & $0.438^{* * *}$ \\
2017 & $0.369^{* * *}$ & $0.498^{* * *}$ \\
2018 & $0.377^{* * *}$ & $0.544^{* * *}$ \\
\hline Note. ${ }^{*} p<0.1,{ }^{* *} p<0.05,{ }^{* * *} p<0.01$. &
\end{tabular}

found in Figure 4. Most of the provinces are located in quadrant I and quadrant III, representing $70.97 \%$ and $77.42 \%$ of the total number in 2013 and 2018, respectively. The provinces falling into quadrant I are coastal provinces, while those falling into quadrant III are mainly inland provinces.

The results show that the geographical effect cannot be ignored in the study of digital financial inclusion and household consumption. Otherwise, the estimation would be invalid.

\subsection{Spatial Effect Test}

4.3.1. Lagrange Multiplier (LM) Test. Before building the SDM model, we first use LM tests to test the existence of the spatial effect. The tests determine whether SAR or SEM can describe the features of the data better than the OLS model, which does not consider spatial interaction. We make judgments by using the LM test $\left(\mathrm{LM}_{\mathrm{SAR}}, \mathrm{LM}_{\mathrm{SEM}}\right)$ designed by Anselin (1988) and the robust LM test (Robust LM $_{\mathrm{SAR}}$, Robust $\mathrm{LM}_{\mathrm{SEM}}$ ) developed by Anselin et al. (1996) [33, 40]. If the results of $\mathrm{LM}_{\mathrm{SAR}}$ and $\mathrm{LM}_{\mathrm{SEM}}$ are nonsignificant, the OLS model should be selected. However, if either of the statistics are significant, spatial econometric models should be built. We should select the model with the larger LM statistic under the same condition of significance. If we are not able to conclude merely according to the LM statistic, the robust LM statistics are needed, and the model with the larger robust $\mathrm{LM}$ statistic under the same significance is considered more convincing.

Table 5 shows the results of the LM test and the robust LM test. Only the statistics of the SAR model $\left(\mathrm{LM}_{\mathrm{SAR}}\right.$ and Robust $\mathrm{LM}_{\mathrm{SEM}}$ ) pass the significance level test of $1 \%$, demonstrating the existence of spatiality. Thus, it is more appropriate to select SAR than SEM.

4.3.2. Likelihood Ratio Tests (LR) and Wald Test. Elhorst (2010) pointed out that if the OLS model is not accepted by the LM tests, then we should examine whether the SDM can be transformed into the SAM or SEM based on the results of the LR test and the Wald test [41].

The LR test and the Wald test are built to test the hypotheses $H_{0}: \theta=0$ and $H_{0}: \theta+\rho \beta=0$ (the letters are defined in equation (2)). The results of the LR test and the Wald test are presented in Table 6. As Table 6 indicates, the 


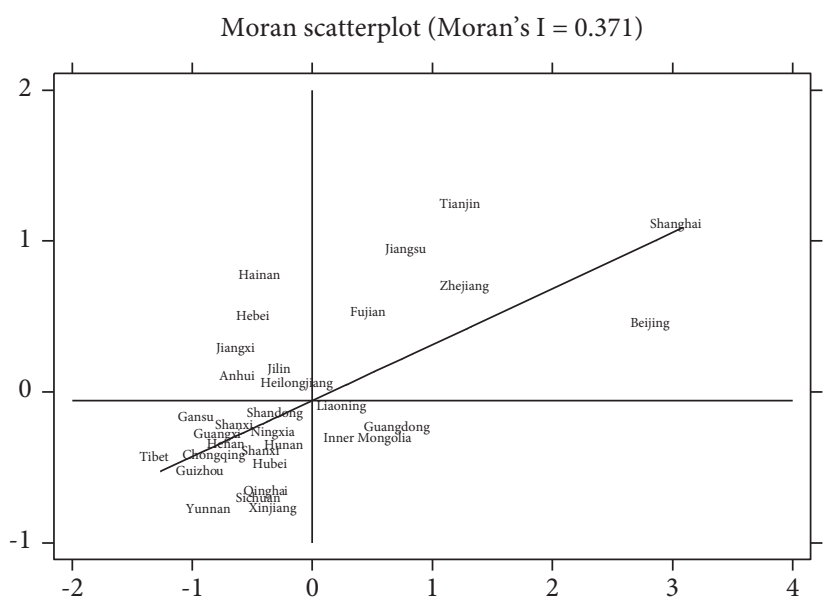

(a)

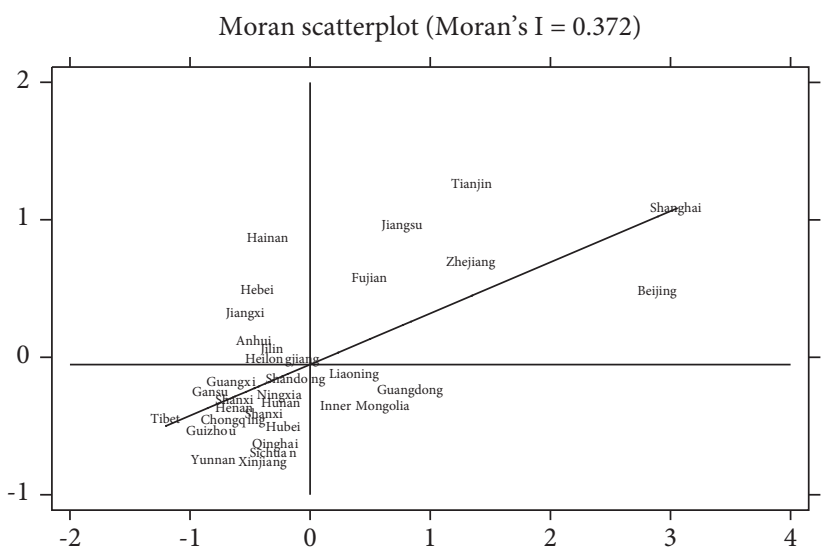

(c)

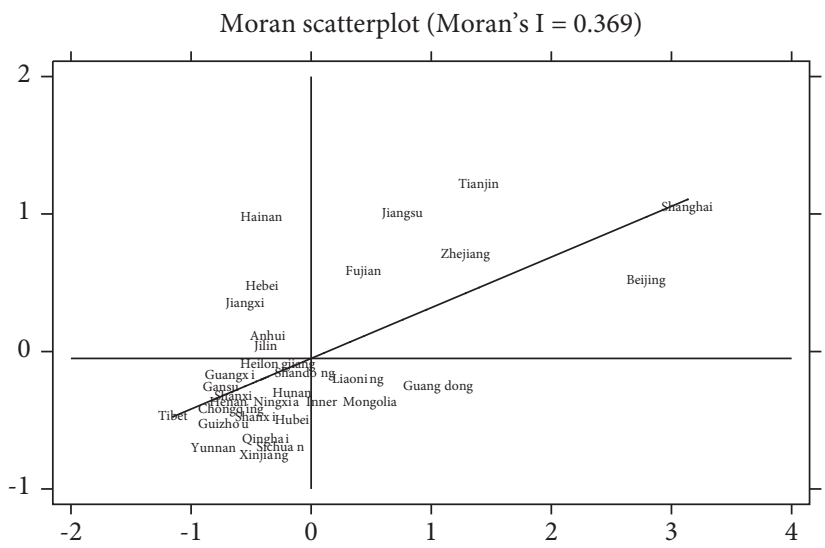

(e)

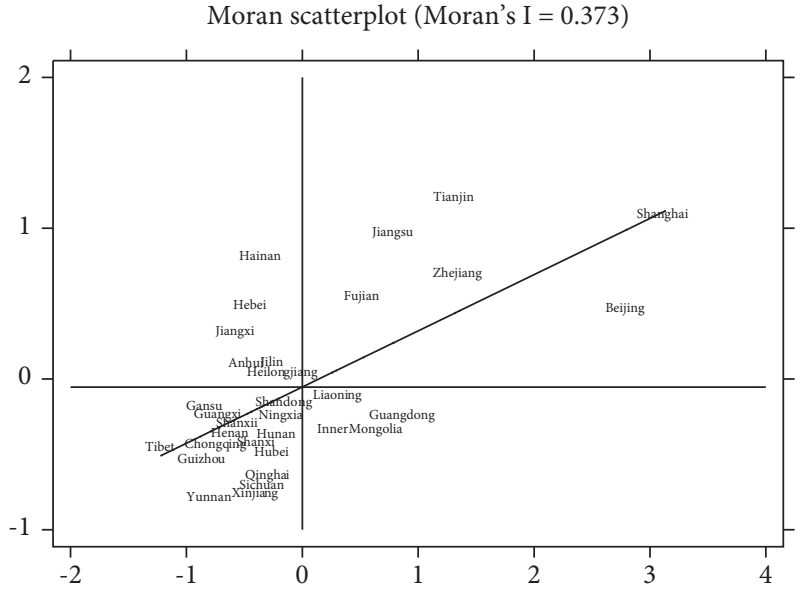

(b)

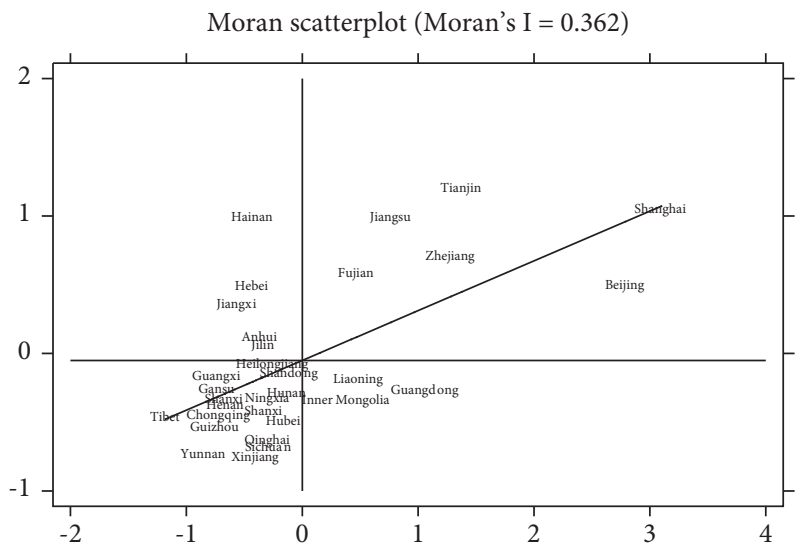

(d)

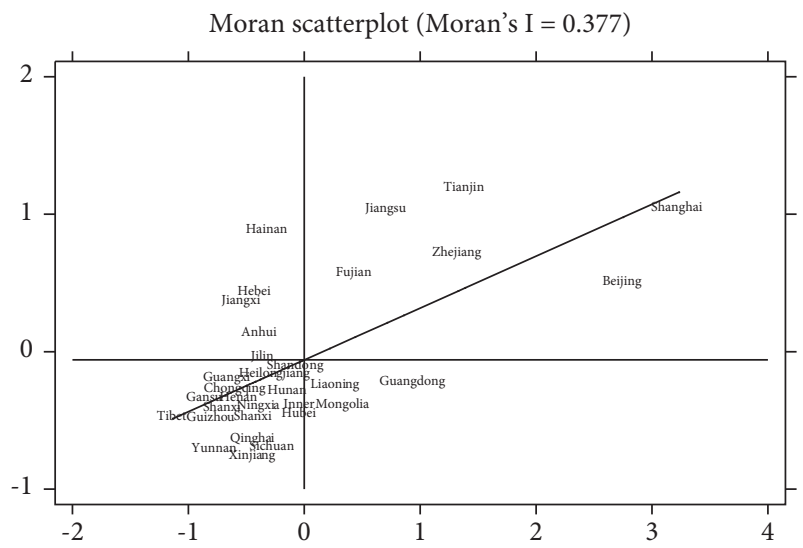

(f)

Figure 3: Scatter plots of the local Moran's I index for household consumption (2013-2018). (a) Household consumption of 2013. (b) Household consumption of 2014. (c) Household consumption of 2016. (d) Household consumption of 2017. (e) Household consumption of 2018 .

statistics are all significant at the $1 \%$ level, proving that the SDM cannot be simplified, and the SDM is the final choice.

4.3.3. Hausman Test. Before model construction, the Hausman test is needed to determine whether random effects or fixed effects are more appropriate. According to the result, the statistic value is 227.87 and is significant at the $1 \%$ level, so we choose fixed effects instead of random effects.

4.4. The Effect of Digital Financial Inclusion on Household Consumption. We report the empirical results of the OLS model and spatial model in column (1) and column (2) in 


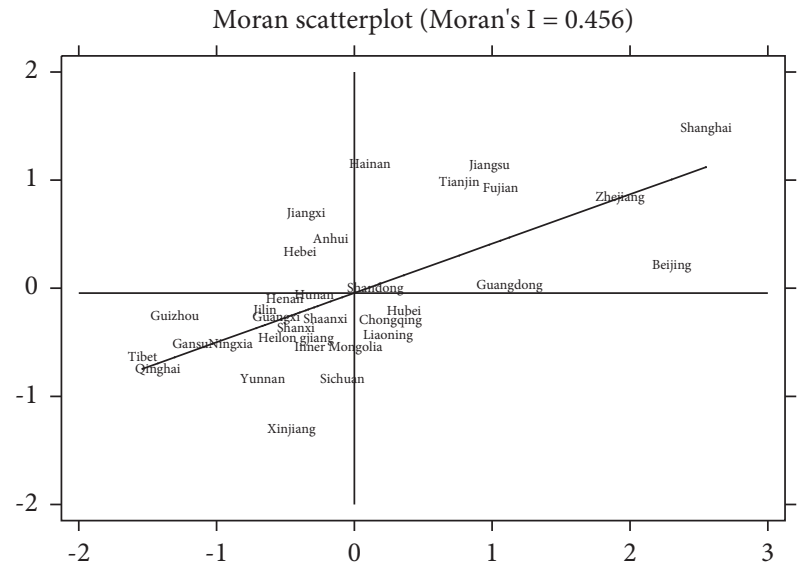

(a)

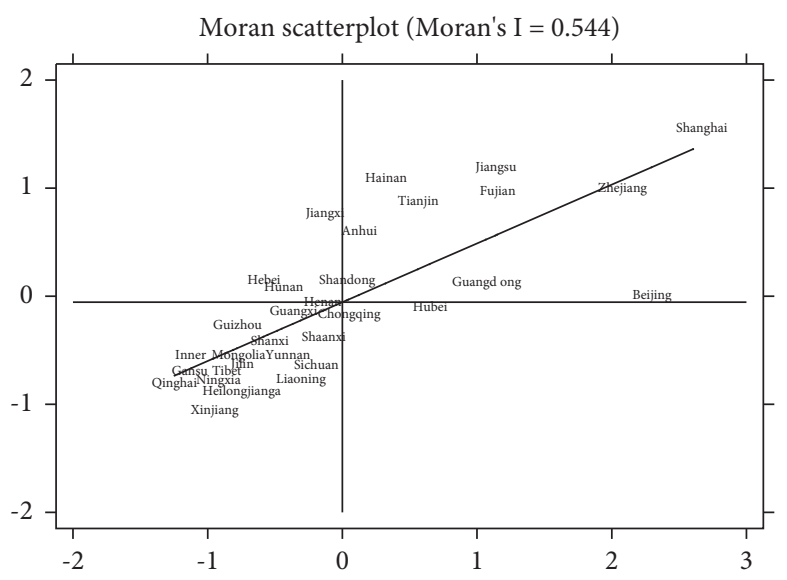

(b)

Figure 4: Scatter plots of the local Moran's I index for digital financial inclusion (2013 and 2018). (a) Digital Financial Inclusion Index in 2013. (b) Digital Financial Inclusion Index in 2018.

Table 7, respectively. For the results of the spatial model in column (2), researchers pointed out that the coefficients should be decomposed to prevent estimation bias caused by the feedback loop effect. The decomposition results are shown in Table 8. The coefficient of digital financial inclusion in the OLS model is not significant, while the coefficients in the decomposition in Table 8 are all significant. This difference implies that the OLS result might be contaminated by ignoring variable bias [42]. That is, the nonsignificance of the OLS model can be attributed to endogeneity caused by variable omission. According to the tests presented above and the fact that production factors flow across boundaries with increasing frequency, we know that provinces are increasingly correlated. Therefore, if we fail to consider spatial factors, the estimation will be invalid. Overall, the OLS model fails to consider the important effects of variables from surrounding areas, and spatial models can partly solve this problem.

The parameter of spatial autoregression $\rho$ is -0.6400 and is significant at the $1 \%$ level. This phenomenon might be interpreted as follows. First, in general, household consumption among regions presents a competitive relationship because resources are limited as a whole. Resources are usually allocated according to demand, which contributes to a spatial crowding-out effect [5]. This indicates that higher household consumption demand in one region may increase the consumer goods transmission from its neighbors and accordingly inhibit household consumption in those provinces. Second, the increasing development of transportation systems has significantly facilitated population movement between different areas. People tend to move to regions with higher living standards and more kinds of consumer goods, which accelerates regional differences in household consumption. From this viewpoint, it is imperative to develop policies that strengthen cooperation among provinces, promote effective resource allocation, and increase the aggregate supply of goods to form a balanced consumption pattern and a win-win situation.
TABLe 5: Results of the LM test and robust LM test.

\begin{tabular}{lcc}
\hline Test method & Statistic & $p$-value \\
\hline LM $_{\text {SAR }}$ & $12.782^{* * *}$ & $\leq 0.01$ \\
Robust LM $_{\text {SAR }}$ & $12.877^{* * *}$ & $\leq 0.01$ \\
LM $_{\text {SEM }}$ & 0.953 & 0.33 \\
Robust LM & 1.048 & 0.31 \\
\hline
\end{tabular}

Note. ${ }^{*} p<0.1,{ }^{* *} p<0.05,{ }^{* * *} p<0.01$.

4.5. Decomposition of the Spatial Spillover Effect. In the ordinary model, the coefficient $\beta$ can directly reflect the impact of independent variables on the dependent variable. However, in the case of spatial econometric models, the explanation of coefficients is more complex [43]. Anselin and LeGallo (2006) and Kelejian and Prucha (2007) pointed out that for SEMs with the spatial autoregression term, the coefficients should be particularly explained to prevent estimation bias caused by the feedback loop effect [44, 45]. Thus, we decompose the spatial spillover effect into the direct effect, the indirect effect, and the total effect. The decomposition results of the SDM are listed in Table 8.

For the effect of digital financial inclusion, a $1 \%$ improvement in digital financial inclusion directly increases household consumption by $0.2207 \%$ but indirectly decreases it by $0.1289 \%$, and the net effect is a total increase of $0.0917 \%$. By providing diversified financial services, such as mobile payments, online loans, Internet insurance, and Internet finance, digital financial inclusion may affect household consumption in four dimensions. Digital payment platforms give rise to online shopping, which can improve information asymmetry and diversify commodities in the consumer market, thus boosting household consumption. Digital credit expands the way residents obtain loans, eases their liquidity constraints, and, as a result, promotes household consumption. Online insurance makes it easier for residents to obtain access to insurance services, thus smoothing consumption when individuals face adverse shocks. Online investment provides households with accessible investment services and increases their investment income, accordingly 
TABLE 6: Results of the LR test and the Wald test.

\begin{tabular}{lcc}
\hline LR/Wald & Statistic & $p$-value \\
\hline LR test (SDM vs. SAR) & $91.32^{* * *}$ & $\leq 0.01$ \\
LR test (SDM vs. SEM) & $72.29^{* * *}$ & $\leq 0.01$ \\
Wald test & $88.34^{* * *}$ & $\leq 0.01$ \\
\hline
\end{tabular}

Note. ${ }^{*} p<0.1,{ }^{* *} p<0.05$, and ${ }^{* * *} p<0.01$.

TABLE 7: Results of the nonspatial model and SDM.

\begin{tabular}{lcc}
\hline Variables & (1) panel & $(2)$ SDM \\
\hline Ln(DFI) & $0.0509(1.14)$ & $0.1956^{* * *}(3.96)$ \\
Ln(Incom) & $0.7772^{* * *}(11.67)$ & $0.6141^{* * *}(5.78)$ \\
Ln(Hum) & $0.0792^{* *}(1.98)$ & $0.0357(1.11)$ \\
Trans & $0.0254^{* * *}(5.17)$ & $0.0282^{* * *}(8.17)$ \\
Fisc & $0.1457^{*}(1.65)$ & $0.2743^{* * *}(3.89)$ \\
Indus & $-0.4043(-0.84)$ & $0.6768^{*}(1.70)$ \\
Open & $0.3203(0.49)$ & $-0.3720(-0.81)$ \\
Pop & $-0.3142(-0.11)$ & $5.7158^{* * *}(2.64)$ \\
$\mathrm{w}^{*} \operatorname{Ln}(\mathrm{DFI})$ & & $-0.0421(-0.53)$ \\
$\mathrm{w}^{*} \ln ($ Incom $)$ & & $0.4967^{* *}(2.21)$ \\
$\mathrm{w}^{*} \ln ($ Hum $)$ & & $0.5457^{* * *}(8.58)$ \\
$\mathrm{w}^{*}$ (Trans) & & $0.0439^{* * *}(4.82)$ \\
$\mathrm{w}^{*}$ (Fisc) & & $0.0535(0.41)$ \\
$\mathrm{w}^{*}$ (Indus) & & $0.9989(1.20)$ \\
$\mathrm{w}^{*}$ (Open) & & $-0.4187(-0.46)$ \\
$\mathrm{w}^{*}$ (Pop) & & $-0.6529(-0.17)$ \\
$\rho$ & & $-0.6400^{* * *}(-5.80)$ \\
$\theta$ & & $0.0002^{* * *}(9.20)$ \\
$R$-square & & 0.4875 \\
\hline
\end{tabular}

Note. z-values are in parentheses. ${ }^{*} p<0.1,{ }^{* *} p<0.05$, and ${ }^{* * *} p<0.01$.

TABle 8: Decomposition of the spatial spillover effect at the national level.

\begin{tabular}{lccc}
\hline Variables & Direct effects & Indirect effects & Total effects \\
\hline Ln(DFI) & $0.2207^{* * *}(3.63)$ & $-0.1289^{*}(-1.72)$ & $0.0917^{* *}(2.10)$ \\
Ln(Incom) & $0.5860^{* * *}(4.90)$ & $0.0879(0.49)$ & $0.6738^{* * *}(5.69)$ \\
Ln(Hum) & $-0.0373(-0.99)$ & $0.3963^{* * *}(7.18)$ & $0.3589^{* * *}(8.19)$ \\
Trans & $0.0248^{* * *}(5.47)$ & $0.0190^{* * *}(2.58)$ & $0.0440^{* * *}(7.54)$ \\
Fisc & $0.2756^{* * *}(2.90)$ & $-0.0823(-0.72)$ & $0.1933^{* *}(2.19)$ \\
Indus & $0.6050(1.52)$ & $0.4900(0.84)$ & $1.0952^{*}(1.93)$ \\
Open & $-0.3343(-0.64)$ & $-0.1844(-0.25)$ & $-0.5187(-0.81)$ \\
Pop & $5.8262^{* *}(2.43)$ & $-2.6660(-0.86)$ & $3.1602(1.50)$ \\
\hline Note. z-values are in parentheses. ${ }^{*} p<0.1,{ }^{* *} p<0.05$, and $^{* * *} p<0.01$.
\end{tabular}

improving their level of consumption. As a whole, by providing a variety of financial services, digital financial inclusion increases the actual and expected income of residents, thus influencing their purchasing decisions. For the negative indirect effect, it seems that the negative spatial spillover effect outweighs the positive effect. The negative indirect effect suggests a negative spatial dependency in determining household consumption in neighboring provinces. As mentioned above, the most plausible explanation may be the interprovincial movements of capital, knowledge, high-skilled laborers, and even innovative enterprises, which are increasingly regarded as local growth drivers. The movements can mainly be attributed to easier financial service access induced by the advanced digital financial inclusion of neighboring areas. Taking small and medium-sized enterprises (SMEs) as an example, SMEs in China have long faced financial restrictions linked to traditional finance, and digital financial inclusion can ease this problem [46]. Therefore, these enterprises are more likely to move from provinces with a low level of digital financial inclusion to those with a high level. The majority of SMEs are innovative companies with much potential in economic terms, and thus, the unbalanced pattern of economic development will worsen. Overall, provinces with advanced digital financial inclusion can develop better and attract more resources and residents from a province with a lower level of digital financial inclusion, thereby negatively influencing economic development and household consumption in the province. The vampire effect is obvious [34]. For policymakers, it is essential to balance the regional development of digital financial inclusion in terms of quantity and coverage. By doing so, digital financial inclusion can have an immeasurable influence on household consumption promotion at the national level in the future.

For the impact of household income, the direct, indirect, and total effects are all positive. The direct and total effects are significant at the $1 \%$ level, while the indirect effect is not significant. A $1 \%$ increase in household income will lead to a growth of $0.5860 \%$ in household consumption, indicating that household income is one of the main engines of consumption. This result is in accordance with Keynes (1936), Friedman (1957), and Grunberg and Modigliani (1954) [47-49]. They pointed out that deposits and consumption depend on income. They believed that consumers would consume according to their income level, and as their income increases, people spend more on consumption. The indirect effect indicates that a $1 \%$ growth in the income of surrounding provinces drives the growth of consumption in the local province by $0.0879 \%$, showing mutual promotion and synergy in terms of the effect of household income. Although the impact of household income on household consumption in the sample is not very obvious, it is still meaningful for helping China stimulate household consumption.

Transport infrastructure has significantly positive direct, indirect, and total effects on household consumption, with values of $0.0248,0.0190$, and 0.0440 , respectively. This result is in accordance with that of Zhang and Chen (2003). They held that modernized traffic networks can attract capital, technology, and talent resources and thus are conducive to economic development and consumption growth [50]. China's transportation system usually links a province to its surroundings. As a result, the effect of transportation infrastructure in China presents a significant agglomeration effect of mutual promotion and a spatial spillover effect. As transportation infrastructure is further improved, these agglomeration and spillover effects are increasingly enhanced. However, in recent years, the existing transportation systems have not met the ever-growing demand of population explosion brought about by urbanization and the two-child policy. Economic development is also restricted by traffic congestion and the shortage of transportation resources. Accordingly, it is essential to invest more in road expansion and transportation construction and to 
better support the driving role of transportation in household consumption [34].

From the perspective of human capital, the indirect and total effects are positive at the $1 \%$ significance level, while the direct effect is exceptional, being negative and nonsignificant. The positive indirect effect may be explained by imitative behavior: to keep up with the economic development of their neighbors, local governments are inclined to observe and imitate the policies of their neighbors. An advanced education environment provides a strong impetus for economic development and household consumption. Hence, the education level of one province can be conditional on that of its neighbors, resulting in positive spillover effects of the education environment among these regions.

Regarding fiscal expenditure, the local and total impacts are significantly positive, but the indirect effect shows a reserved result, as it is a negative externality and is not significant. According to the precautionary savings hypothesis, when the expected income in the future is uncertain, consumers will become cautious. They will increase savings to deal with the possible risks caused by the uncertainty of income [18]. Researchers name this kind of savings caused by the uncertainty of future income precautionary savings. Carroll (1994) supported the conclusion that the primary motivation for savings is to protect against accidents [30]. Based on the theory, as government spending increases and the social security system improves, the precautionary saving motive becomes less crucial [51]. In addition, macroeconomics considers fiscal expenditure a form of income redistribution that can increase the household income of the poor and alleviate income imbalance. Compared with high-income households, low-income households have more potential for consumption as income increases [52]. As a result, fiscal expenditure can promote household consumption as a whole [53]. Moreover, government policies, such as offering subsidies for countryside inhabitants to buy home appliances, can directly boost household consumption. The negative indirect effect means that increased government spending can reduce consumption activities in neighboring cities, and it can be interpreted by the crowding-out theory. The residents living in a province may be attracted by the better financial, sanitation, and living conditions of nearby places. These results remind policymakers to comprehensively consider the situations of the local province and its neighbors when making full use of "the visible hand".

The direct and indirect effects of the industrial structure are positive but statistically nonsignificant. As a less energyintensive industry, service sector is expected to greatly encourage economic development and promote consumption when expands. Upgrading of the industrial structure can also make production more effective, thus lowering the price of products. Moreover, the prosperity of the tertiary industry diversifies goods and provides households with more options. Although the coefficients of the direct and indirect effects are statistically nonsignificant, they do not suggest that industrial structure is of no significance for household consumption. We tend to interpret that the tertiary industry has a low degree of development, and the current scale of development is not enough to have effects on household consumption. Thus, to increase household consumption, it is essential to promote the upgrading of the industrial structure. The positive but nonsignificant indirect effect implies that the optimization of the industrial structure in nearby provinces can boost overall consumption, implying positive contagion impacts from industrial upgrading. The total effect is significantly positive, which implies that a motivating function on consumption exists, although the direct and indirect effects have not yet become significant.

The coefficients of the direct, indirect, and total effects of openness are $-0.3343,-0.1844$, and -0.5187 , respectively, confirming that the degree of openness hinders the consumption behavior of households. This superficially counterintuitive result is mainly attributed to the adverse effects brought about by the international commodity trade. Import and export trade crowds the domestic market, causing consumer prices to rise and thus restricting the growth of regional household consumption. The negative coefficient of the indirect effect proves an external spillover effect on consumption activities in China. Promising import and export projects are usually rare. An increase in import and export projects in a region encourages foreign investors to seek more profitable opportunities in neighboring regions, thus influencing the neighbors' consumption. The negative effects indicate that the fair taxing and reasonable pricing policies of import goods are instrumental in promoting household consumption. However, none of the three coefficients are significant, proving that the effect of openness is relatively limited. This result may be because China has been opening up for a long period, and the effect of opening up has levelled off.

The last point relates to population density. The direct impact is significantly positive, but the indirect effect is nonsignificantly negative. The growth of the population encourages household consumption activities, but the increase in the population in surrounding areas decreases such activities, which may result from a complete consumer goods transmission system. When the number of people living in nearby provinces increases, their demands on the local province increase, and the supply they provide for the local province decreases. Overall, it is beneficial to consider the population density when making consumption promotion policies for an area.

4.6. Endogeneity Test. There may be endogeneity problems caused by reverse causality, variable omission, etc. To further address this problem, appropriate instrumental variables are required. Based on Zhang and $\mathrm{Hu}$ [54], we use the oneperiod lag of the digital financial inclusion index as its instrumental variable to perform the endogeneity test. Because the level of digital financial inclusion with a one-period lag is related to its current level, and the past level of digital financial inclusion cannot be affected by the current household consumption. Table 9 shows the results. According to the decomposition results, the coefficient of digital financial inclusion is significantly positive, and the coefficient of the 
TABLE 9: Decomposition results of the endogeneity test.

\begin{tabular}{lccc}
\hline Variables & Direct effects & Indirect effects & Total effects \\
\hline Ln(DFI) & $0.2112^{* * *}(3.35)$ & $-0.0951^{*}(-1.67)$ & $0.1162^{* *}(1.98)$ \\
Control & YES & YES & YES \\
\hline Note. z-values are in parentheses. ${ }^{*} p<0.1,{ }^{* *} p<0.05$, and ${ }^{* * *} p<0.01$.
\end{tabular}

spatial lag term is significantly negative, which is consistent with the baseline regression.

4.7. Robustness Analysis. To ensure the robustness of the results, we re-estimate the SDM using a geographic distance spatial weight matrix (calculated by the reciprocal of the longitude and latitude distances between two provinces). Table 10 presents the robustness results of spatial effects based on the geographic distance spatial weight. Although there may be some inconsistency in amplitude and significance level, the direction of the impact and the main conclusions of the core independent variable remain unchanged. The necessity of adopting spatial models is proven again. The improvement in digital financial inclusion will promote household consumption in the local province and reduce household consumption in neighboring provinces.

4.8. Comparison of Spatial Effects between Urban and Rural Regions. There is an urban-rural dual structure in China, which is mainly manifested in the mode of economic development. The urban economy is based on modern largescale industrial production, while the rural economy is based on small-scale farming. The difference contributes to the advanced infrastructure of urban areas and the consumption gap between cities and the countryside. As a form of financial inclusion, digital financial inclusion can reach consumers in remote areas who otherwise would not be covered by traditional financial institutions. Consequently, it can narrow the consumption gap and improve the urbanrural dual structural system. This section compares the spatial effect of urban and rural regions, and the results of the core in dependent variable are shown in Table 11.

As shown in the results of the subregions in Table 11, the direct effects of digital financial inclusion on the household consumption of urban and rural regions are all positively significant. The direct effect of urban areas is 0.2657 , which is lower than the number of rural areas (0.3864), proving that digital financial inclusion has a smaller promoting effect on the consumption of households living in cities. A possible interpretation is that digital financial inclusion can eliminate the restrictions of financial thresholds. Owing to financial repression, the financial threshold brings about disparities in financial availability. High-income groups living in cities have substantial financial resources. They can enjoy convenient financial services because of their advantages in geography and capital accumulation. However, due to geographical disadvantages and because their capital accumulation restrictions cannot reach the wealth threshold level, lowincome groups living in less-developed regions are not able to easily obtain access to financial services. They face more
TABLE 10: Robustness test.

\begin{tabular}{lccc}
\hline Variables & Direct effects & Indirect effects & Total effects \\
\hline Ln(DFI) & $0.3522^{* * *}(4.59)$ & $-0.3098^{* *}(-2.29)$ & $0.0424(0.49)$ \\
Ln(Incom) & $0.7767^{* * *}(5.64)$ & $-0.4626^{*}(-1.73)$ & $0.3141(1.47)$ \\
Ln(Hum) & $-0.0236(-0.61)$ & $0.2979^{* * *}(3.33)$ & $0.2745^{* * *}(3.26)$ \\
Trans & $0.0247^{* * *}(5.22)$ & $0.0317^{* * *}(3.36)$ & $0.0564^{* * *}(5.38)$ \\
Fisc & $0.2292^{* *}(2.24)$ & $-0.0451(-0.23)$ & $0.1841(1.04)$ \\
Indus & $0.3371(0.76)$ & $0.6041(0.79)$ & $0.9412(1.08)$ \\
Open & $-0.3534(-0.62)$ & $0.0192(0.02)$ & $-0.3342(-0.32)$ \\
Pop & $6.3964^{* *}(2.09)$ & $-6.531^{*}(-1.67)$ & $-0.1348(-0.05)$ \\
\hline Note. z-values are in parentheses. ${ }^{*} p<0.1,^{* *} p<0.05$, and ${ }^{* * *} p<0.01$.
\end{tabular}

TABLE 11: The effect of digital financial inclusion on urban and rural regions.

\begin{tabular}{lccc}
\hline Regions & Direct effects & Indirect effects & Total effects \\
\hline Urban regions & $0.2657^{* * *}(2.86)$ & $-0.1818(-1.02)$ & $0.0838(0.47)$ \\
Rural regions & $0.3864^{* * *}(3.76)$ & $-0.2502(-1.59)$ & $0.1361(1.02)$ \\
\hline
\end{tabular}

Note. $z$-values are in parentheses. ${ }^{*} p<0.1,{ }^{* *} p<0.05$, and ${ }^{* * *} p<0.01$.

liquidity constraints and are more impacted by the marginal effect of digital finance on consumption. Overall, digital financial inclusion can dramatically lower the cost of financial services and make financial resources more available. Therefore, low-income people can have broader and easier access to credit, and their credit restrictions can be eased, which is beneficial to promote their consumption.

However, the total effects of both areas are not significant. This may be because digital financial inclusion is still underdeveloped, so it cannot make a difference when affecting the disadvantaged people and the main public. Although digital financial inclusion has developed rapidly in recent years, it is still far from developed. Policymakers should create a friendly environment to encourage the development of digital financial inclusion and make it easier for disadvantaged people to gain access to financial services, which is the primary goal of financial inclusion.

\section{Conclusion}

Based on panel data for 31 provinces from 2013 to 2018 in China, we study the impact of digital financial inclusion on household consumption. We find that household consumption and the development of digital financial inclusion show geographical agglomeration. The spatial distribution of China's household consumption presents a ladder distribution from coastal to inland areas because of the unbalanced pattern of economic development. The levels of digital financial inclusion in China decline with the distance from Hangzhou, partly because of the difficulties of promoting and diffusing digital finance from Hangzhou. By constructing spatial panel models and disaggregating spatial spillover effects into the direct, indirect, and total effects, we find that digital financial inclusion has a positive direct impact and an adverse indirect impact on household consumption at the national level. Further analysis based on subsamples shows that the influence of digital financial inclusion on household consumption is more significant for 
rural residents than for urban residents. However, the difference is not significant because of the underdevelopment of digital financial inclusion.

Our findings have the following meaningful implications for policymakers. First, because the development of digital financial inclusion can boost household consumption and improve the dual urban-rural system, policymakers should focus on its driving impact and make no effort to promote it. However, it is not enough to consider only local conditions because provinces are increasingly related. When making policies, it is crucial to assess the condition of peripheral regions and view provinces as a whole. Third, provinces are expected to develop in a coordinated way by cooperating with surrounding provinces and realizing effective source distribution to form a balanced pattern among different provinces, resulting in a win-win situation.

The research in this paper has certain limitations. First, the data are at the provincial level, so they may have specific sample deviations and cannot reflect individual features. If micro data could be accessed in the future, researchers could compare the new outcomes using micro data with the conclusions drawn from this paper. Second, this paper uses data from 2013 to 2018, which is not very recent. A policy for making data publicly available in China is urgent. Third, as this paper involves data only on aggregate household consumption, it is advised to comprehensively investigate different types of consumer goods that households buy.

\section{Data Availability}

The data of the Digital Financial Inclusion Index used to support the findings of this study may be released upon application to the Institute of Digital Finance, Peking University, which can be contacted at guofengsfi@163.com. The household consumption data and the control variables used to support the findings of this study are released by the National Bureau of Statistics.

\section{Conflicts of Interest}

The authors declare that they have no conflicts of interest.

\section{References}

[1] J. T. Lai, I. K. M. Yan, X. Yi, and H. Zhang, "Digital financial inclusion and consumption smoothing in China," China and World Economy, vol. 28, no. 1, pp. 64-93, 2020.

[2] A. A. Levchenko, "Financial liberalization and consumption volatility in developing countries," IMF Staff Papers, vol. 52, pp. 237-259, 2005.

[3] W. R. Tobler, "A computer movie simulating urban growth in the Detroit region," Economic Geography, vol. 46, pp. 234-240, 1970.

[4] J. S. Duesenberry, "Income, saving, and the theory of consumer behavior," The Review of Economics and Statistics, vol. 33, p. 111, 1949.

[5] Y. Funashima and Y. Ohtsuka, "Spatial crowding-out and crowding-in effects of government spending on the private sector in Japan," Regional Science and Urban Economics, vol. 75, pp. 35-48, 2019.
[6] Y. Lv, W. Chen, and J. Cheng, "Modelling dynamic impacts of urbanization on disaggregated energy consumption in China: a spatial Durbin modelling and decomposition approach," Energy Policy, vol. 133, Article ID 110841, 2019.

[7] L. Klapper, D. Singer, S. Ansar, and J. Hess, Financial Risk Management In Agriculture: Analyzing Data From A New Module Of The Global Findex Database, The World Bank, Washington, DC, USA, 2019.

[8] D. H. Vo, N. T. Nguyen, and L. Thi-Hong Van, "Financial inclusion and stability in the Asian region using bank-level data," Borsa Istanbul Review, vol. 21, no. 1, pp. 36-43, 2021.

[9] W. Zhong and T. Jiang, "Can internet finance alleviate the exclusiveness of traditional finance? evidence from Chinese P2P lending markets," Finance Research Letters, vol. 40, Article ID 101731, 2020.

[10] P. Gomber, J.-A. Koch, and M. Siering, "Digital finance and fintech: current research and future research directions," Journal of Business Economics, vol. 87, no. 5, pp. 537-580, 2017.

[11] Q. Song, J. Li, Y. Wu, and Z. Yin, “Accessibility of financial services and household consumption in China: evidence from micro data," The North American Journal of Economics and Finance, vol. 53, Article ID 101213, 2020.

[12] J. Li, Y. Wu, and J. J. Xiao, "The impact of digital finance on household consumption: evidence from China," Economic Modelling, vol. 86, pp. 317-326, 2020.

[13] R. Thaler, "Toward a positive theory of consumer choice," Journal of Economic Behavior \& Organization, vol. 1, no. 1, pp. 39-60, 1980.

[14] J. Fan, L. Tang, W. Zhu, and B. Zou, "The alibaba effect: spatial consumption inequality and the welfare gains from e-commerce," Journal of International Economics, vol. 114, pp. 203-220, 2018.

[15] S. P. Zeldes, "Consumption and liquidity constraints: an empirical investigation," Journal of Political Economy, vol. 97, no. 2, pp. 305-346, 1989.

[16] A. Deaton, The Analysis of Household Surveys: A Microeconometric Approach to Development Policy, The World Bank, Washington, DC, USA, 1997.

[17] Y. Pierrakis and L. C. Collins, A New Innovative Model Of Providing Funding To Projects And Businesses, Catholic University of Louvain, Louvain-la-Neuve, Belgium, 2013.

[18] H. E. Leland, "Saving and uncertainty: the precautionary demand for saving," Uncertainty in Economics, Elsevier, vol. 82, no. 3, , pp. 465-473, 1968.

[19] J. Grossman and M. Tarazi, Serving Smallholder Farmers: Recent Developments in Digital Finance, CGAP, Washington, DC, USA, 2014.

[20] F. Guo, S. T. Kong, and J. Wang, "General patterns and regional disparity of internet finance development in China: evidence from the peking university internet finance development index," China Economic Journal, vol. 9, no. 3, pp. 253-271, 2016.

[21] X. Liu, J. Zhu, J. Guo, and C. Cui, "Spatial association and explanation of China's digital financial inclusion development based on the network analysis method," Complexity, vol. 2021, Article ID 6649894, 13 pages, 2021.

[22] G. Feng, K. Tao, and W. Jingyi, “The spatial agglomeration effect of internet finance-evidence from the financial development index," Studies of International Finance, vol. 8, 2017.

[23] B. Zhu, J. He, and S. Zhai, "Does financial inclusion create a spatial spillover effect between regions? Evidence from China," Emerging Markets Finance and Trade, vol. 55, no. 5, pp. 980-997, 2019. 
[24] Y. Su, Z. Li, and C. Yang, "Spatial interaction spillover effects between digital financial technology and urban ecological efficiency in China: an empirical study based on spatial simultaneous equations," International Journal of Environmental Research and Public Health, vol. 18, no. 16, p. 8535, 2021.

[25] X. Wang and J. Guan, "Financial inclusion: measurement, spatial effects and influencing factors," Applied Economics, vol. 49, no. 18, pp. 1751-1762, 2017.

[26] J. Huang, W. Zhang, and W. Ruan, "Spatial spillover and impact factors of the internet finance development in China," Physica A: Statistical Mechanics and Its Applications, vol. 527, Article ID 121390, 2019.

[27] G. Feng, W. Jingyi, W. Fang, K. Tao, Z. Xun, and C. Zhiyun, "Measuring China's digital financial inclusion: index compilation and spatial characteristics," China Economic Quarterly, vol. 19, pp. 1401-1418, 2020.

[28] Y. Shen, C. J. Hueng, and W. Hu, "Measurement and spillover effect of digital financial inclusion: a cross-country analysis," Applied Economics Letters, vol. 28, pp. 1-6, 2020.

[29] J. Álvarez-Gamboa, P. Cabrera-Barona, and H. JácomeEstrella, "Financial inclusion and multidimensional poverty in Ecuador: a spatial approach," World Development Perspectives, vol. 22, Article ID 100311, 2021.

[30] C. D. Carroll, "How does future income affect current consumption?” Quarterly Journal of Economics, vol. 109, no. 1, pp. 111-147, 1994.

[31] O. P. Attanasio and G. Weber, "Is consumption growth consistent with intertemporal optimization? evidence from the consumer expenditure survey," Journal of Political Economy, vol. 103, no. 6, pp. 1121-1157, 1995.

[32] W. Zhao, "Does health insurance promote people's consumption? new evidence from China," China Economic Review, vol. 53, pp. 65-86, 2019.

[33] L. Anselin, "Lagrange multiplier test diagnostics for spatial dependence and spatial heterogeneity," Geographical Analysis, vol. 20, pp. 1-17, 1988.

[34] G. Qi, W. Shi, K.-C. Lin, K. F. Yuen, and Y. Xiao, "Spatial spillover effects of logistics infrastructure on regional development: evidence from China," Transportation Research Part A: Policy and Practice, vol. 135, pp. 96-114, 2020.

[35] J. A. Donaldson, China's Administrative Hierarchy: The Balance of Power and Winners and Losers within China's Levels of Government, Routledge, Oxfordshire, Uk, 2017.

[36] A. D. Cliff and J. K. Ord, Spatial Processes: Models \& Applications, Taylor \& Francis, Oxfordshire, Uk, 1981.

[37] P. A. P. Moran, "Notes on continuous stochastic phenomena," Biometrika, vol. 37, no. 1-2, pp. 17-23, 1950.

[38] H. Li, C. A. Calder, and N. Cressie, “Beyond Moran's I: testing for spatial dependence based on the spatial autoregressive model," Geographical Analysis, vol. 39, no. 4, pp. 357-375, 2007.

[39] H. Wang, L. Ding, R. Guan, and Y. Xia, "Effects of advancing internet technology on Chinese employment: a spatial study of inter-industry spillovers," Technological Forecasting and Social Change, vol. 161, Article ID 120259, 2020.

[40] L. Anselin, A. K. Bera, R. Florax, and M. J. Yoon, "Simple diagnostic tests for spatial dependence," Regional Science and Urban Economics, vol. 26, no. 1, pp. 77-104, 1996.

[41] J. P. Elhorst, "Applied spatial econometrics: raising the bar," Spatial Economic Analysis, vol. 5, no. 1, pp. 9-28, 2010.

[42] C. Cheng, Y. Hua, and D. Tan, "Spatial dynamics and determinants of sustainable finance: evidence from venture capital investment in China," Journal of Cleaner Production, vol. 232, pp. 1148-1157, 2019.

[43] R. K. Pace and J. P. LeSage, "A sampling approach to estimate the log determinant used in spatial likelihood problems," Journal of Geographical Systems, vol. 11, no. 3, pp. 209-225, 2009.

[44] L. Anselin and J. Le Gallo, "Interpolation of air quality measures in hedonic house price models: spatial aspects," Spatial Economic Analysis, vol. 1, no. 1, pp. 31-52, 2006.

[45] H. H. Kelejian and I. R. Prucha, "HAC estimation in a spatial framework," Journal of Econometrics, vol. 140, no. 1, pp. 131-154, 2007.

[46] L. Yang and Y. Zhang, "Digital financial inclusion and sustainable growth of small and micro enterprises-evidence based on China's new third board market listed companies," Sustainability, vol. 12, no. 9, p. 3733, 2020.

[47] J. M. Keynes, “The general theory of employment," Quarterly Journal of Economics, vol. 51, no. 2, pp. 209-223, 1937.

[48] M. Friedman, "The permanent income hypothesis," in $A$ Theory of the Consumption Function, pp. 20-37, Princeton University Press, Princeton, NJ, USA, 1957.

[49] E. Grunberg and F. Modigliani, "The predictability of social events," Journal of Political Economy, vol. 62, no. 6, pp. 465-478, 1954.

[50] A. Zhang and H. Chen, "Evolution of China's air transport development and policy towards international liberalization," Transportation Journal, vol. 42, no. 3, pp. 31-49, 2003.

[51] M. Browning and A. Lusardi, "Household saving: micro theories and micro facts," Journal of Economic Literature, vol. 34, pp. 1797-1855, 1996.

[52] C. Binkai, "Income inequality and consumption demand: theory and evidence from China," Nankai Economic Studies, vol. 1, 2012.

[53] J. Galí, J. D. López-Salido, and J. Vallés, "Understanding the effects of government spending on consumption," Journal of the European Economic Association, vol. 5, pp. 227-270, 2007.

[54] W. Zhang and Y. Hu, "The effect of innovative human capital on green total factor productivity in the Yangtze River Delta," China population, resources and environment, vol. 30, pp. 106-120, 2020. 